\title{
Ferricarboxy maltose to treat iron deficiency anemia in pregnancy: is it a feasible option?
}

\author{
Reema Kumar Bhatt ${ }^{1 *}$, P. S. Rao ${ }^{2}$, Sanjay Sharma ${ }^{1}$, Chetan Yadav ${ }^{1}$
}

\begin{abstract}
${ }^{1}$ Department of Obstetrics and Gynecology, Army Hospital Research and Referral, Delhi, India
${ }^{2}$ Department of Obstetrics and Gynecology, Command Hospital Airforce, Bangalore, Karnataka, India
\end{abstract}

Received: 13 November 2018

Accepted: 27 November 2018

\section{*Correspondence:}

Dr. Reema Kumar Bhatt,

E-mail: reemakamalbhatt@yahoo.co.in

Copyright: () the author(s), publisher and licensee Medip Academy. This is an open-access article distributed under the terms of the Creative Commons Attribution Non-Commercial License, which permits unrestricted non-commercial use, distribution, and reproduction in any medium, provided the original work is properly cited.

\begin{abstract}
Background: Iron deficiency is a common cause of anaemia in pregnancy which influences the health of mother and developing fetus. Intravenous (IV) iron preparations are considered, when oral iron therapy is ineffective or intolerant. Ferric carboxymaltose is an IV preparation that can be given with ease of administration and better tolerated. The aim of this study was to assess the efficacy and safety of IV ferric carboxymaltose in pregnant mother with all grades of anemia in the second and third trimester.

Methods: This is a prospective observational study where 44 pregnant women with iron deficiency anemia [IDA] received ferric carboxymaltose up to $15 \mathrm{mg} / \mathrm{kg}$ in second and third trimester. The parameters that were taken into account, to assess the effectiveness of the treatment was repeat haemoglobin $[\mathrm{Hb}]$ measurements and the subjective sense of wellbeing in the patient. The safety of the drug was analysed by continuous fetal heart rate [FHR] monitoring during the infusion and observation of any adverse reactions.

Results: Ferric carboxymaltose intravenous infusion significantly increased $\mathrm{Hb}$ levels above baseline values in all women. The Increase in Hb levels were observed at 3- and 6-weeks post infusion therapy. FHR monitoring did not show any drug related unfavourable effect on the fetus. Of the 44 women interviewed, $33(75 \%)$ women reported sense of well-being, 7 (15.9\%) women could not feel any difference after the infusion and $4(9.1 \%)$ patients could not comment. No serious adverse effects were noticed but minor side effects occurred in $3(6.8 \%)$ patients.

Conclusions: This prospective study showed safety and efficacy of ferric carboxymaltose in pregnancy with IDA which is consistent with available observational data.
\end{abstract}

Keywords: Ferric carboxymaltose, Intravenous iron, Iron deficiency anemia severity, Iron deficiency no anemia, Pregnancy, Safety

\section{INTRODUCTION}

Iron deficiency anemia in child bearing age is commonly encountered problem in developing as well as developed countries. ${ }^{1}$ The World Health Organization (WHO) had estimated 32 million pregnant women with anemia and of those, half of the population was ascribed to iron deficiency and therefore, amenable to iron supplementation. ${ }^{2}$ Iron deficiency with or without anemia during pregnancy has associated with significant risk for maternal and fetal morbidity. ${ }^{3}$ Iron-deficiency anemia is common in pregnancy because of fetal as well as placental requirements, and increase in red cell mass, along the course of pregnancy.

For the prevention of iron deficiency in pregnancy, $30 \mathrm{mg}$ of daily iron has been recommended by the experts, which can be readily met by prenatal vitamin 
formulations. Additional iron supplementation is needed for women entering pregnancy associated with anemia. ${ }^{4}$

The rationale behind prevention of iron deficiency anemia in pregnancy is to avoid associated morbidities which includes preterm birth, intrauterine fetal death, fetal growth restriction, low APGAR scores and infection. ${ }^{5}$ The impact of anemia comes to the mother in terms of impaired physical function, increased cardiac failure, and even related death. ${ }^{6-8}$ The effect spills over to the postpartum period leading the mother to postpartum anemia, which is associated with postpartum depression, impaired physical function ${ }^{1}$, and impaired lactation. ${ }^{9-11}$ According to Centre of Disease Control (CDC) recommendations anemia in pregnancy is defined by a haemoglobin level less than $11.0 \mathrm{~g} / \mathrm{dL}$ in both first and third trimesters and less than $10.5 \mathrm{~g} / \mathrm{dL}$ in the second trimester. ${ }^{12,13}$

Supplementation with oral iron is the first-line treatment for pregnancy with iron-deficiency anemia. The Institute of Medicine had recommended daily 30 to $120 \mathrm{mg}$ of elemental iron for pregnant women, but nearly half of pregnant women can suffer from side-effects of oral iron therapy which includes nausea, vomiting, constipation, and epigastric discomfort, often limiting tolerance and affecting compliance, delaying repletion efforts. The several attempts to treat with oral iron more than once daily has also limited benefit because the subsequent doses less effective because of hepcidin feedback inhibition. Intravenous (IV) iron administration overcomes the deficits of oral formulations, and may help to increase iron stores more quickly, however it remains underutilized in IDA in pregnancy, due to perceptions of risk and cost. ${ }^{14-17}$

Intravenous iron is less commonly used as an alternative due to fear of anaphylaxis with iron dextran and long infusion with polymaltose. ${ }^{18}$ The development of dextran free parenteral iron formulations with an improved safety profile, and a more rapid delivery time suggests that intravenous iron should be considered as a mainstay treatment for moderate to severe IDA. ${ }^{19}$ Dextran free Intravenous iron preparations like iron sucrose and ferric carboxymaltose are available. Intravenous Iron sucrose is preferred over oral iron because it increases haemoglobin, with better replenishment of iron stores and definitely better safety profile. ${ }^{20,21}$ However due to its minor side effects which are attributable to its non-physiological properties like high ph and high osmolality has restricted its use. The new Dextran preparation ferric carboxymaltose with properties like near neutral ph, physiological osmolality and increased bioavailability allows additional advantage of single high dose of 1000 $\mathrm{mg}$ in 15 minutes infusion time. ${ }^{22}$ The properties of ferric carboxymaltose make it an attractive alternative to iron sucrose in terms of efficacy, risk profile, patient comfort and convenience, also staff and institutional resource utilization.
There are few clinical studies of ferric carboxymaltose used in pregnancy with iron deficiency anemia. The aim of present study was to assess the correction of iron deficiency anaemia in pregnancy with the use of IV ferric carboxymaltose, to determine the severity of adverse effects of ferric carboxymaltose, and to evaluate its effect on quality of life of women in the post-partum period.

\section{METHODS}

After approval by the Ethics committee of our hospital this prospective study was performed between Jan 2016 and April 2017. Informed consent was taken. Pregnant women with documented IDA, defined as $\mathrm{Hb}<10.5 \mathrm{~g} / \mathrm{dl}$, who presented as outpatients in the obstetrics and gynaecology OPD were recruited to this study and they were administered ferric carboxymaltose infusions. A total of 44 women were included. Authors adopted a longer, slower infusion protocol $(30 \mathrm{~min})$ in order to avoid any side effect in pregnant women. Fetal heart rate was assessed before and after infusion and maternal blood pressure was taken every ten minutes during infusion. Blood samples were collected to measure haemoglobin, and in some cases ferritin levels, prior to infusion and then again, where clinically indicated, at up to three post-infusion visits (at approximately 1,3 and 6 weeks) during routine antenatal visits which were timed with blood collection dates. Women were observed for one-hour post infusion, before being discharged home. EDTA blood sample for hemoglobin was processed in new generation hematology analyzer i.e. ADVIAR $2120 \mathrm{i}$ (Siemens HealthCare). This flow cytometry-based system works on light scatter principle and uses cyanide-free, environment-sensitive colorimetric method for hemoglobin estimation. Serum was separated by centrifugation at room temperature at $1000 \mathrm{rpm}$ for 10 minutes from blood sample collected in sterile vacutainer. Quantitative ferritin level was measured by solid phase sandwich enzyme immunoassay technique based on streptavidin-biotin principle using Automated Immunoanalyzer (Roche Diagnostics).

Medical and pathology data were collated from case notes and electronic laboratory reports. A visit was conducted at a specified time for all 44 patients delivered to evaluate well-being after the infusion. The statistical analysis used was significance of proportion and chi square test was used to derive to results.

\section{RESULTS}

The demographic profile of the women receiving intravenous ferric carboxymaltose for iron deficiency anaemia is mentioned in Table 1. A total of 44 women received infusion of ferric carboxymaltose for antenatal iron deficiency anaemia and their pre-infusion data on haemoglobin values were available for all. Post infusion haemoglobin values were repeated at 1,3 and 6 weeks and again where clinically indicated. All women 
responded to the ferric carboxymaltose treatment with increased Haemoglobin values.

Table 1: Demographic information of women in the study.

\begin{tabular}{|ll|}
\hline Demographic data & Number (\%) \\
\hline Age (years) & $29.3 \pm 5.3$ \\
\hline Gravidity & \\
\hline Primi & $26(59.1 \%)$ \\
\hline $2^{\text {nd }}$ gravida & $14(31.8 \%)$ \\
\hline $3^{\text {rd }}$ gravida & $3(6.8 \%)$ \\
\hline $4^{\text {th }}$ gravida & $1(2.3 \%)$ \\
\hline Mode of delivery & $25(56.8 \%)$ \\
\hline Vaginal (FTND) & $7(15.9 \%)$ \\
\hline Elective Caesarean (EL LSCS) & $7(15.9 \%)$ \\
\hline Emergency Caesarean (EM LSCS) & $3(6.8 \%)$ \\
\hline LSCS & $26.9 \pm 4.8$ \\
\hline Gestational age at intervention (weeks) & $9.47 \pm 1.7$ \\
\hline Haemoglobin at booking (12 weeks) & $12.37 \pm 7.3$ \\
\hline Ferritin at booking (12 weeks) & EM-emergency, \\
\hline FTND-full term normal delivery, EL-elective, & LSCS-lower segment caesarean section. \\
\hline
\end{tabular}

Of the 44 women entered into the study, 26.2(\%11) women were defined as having severe anaemia, while 18.68 women had moderate anaemia and the remaining $55.3 \%$ 25women had mild anaemia.

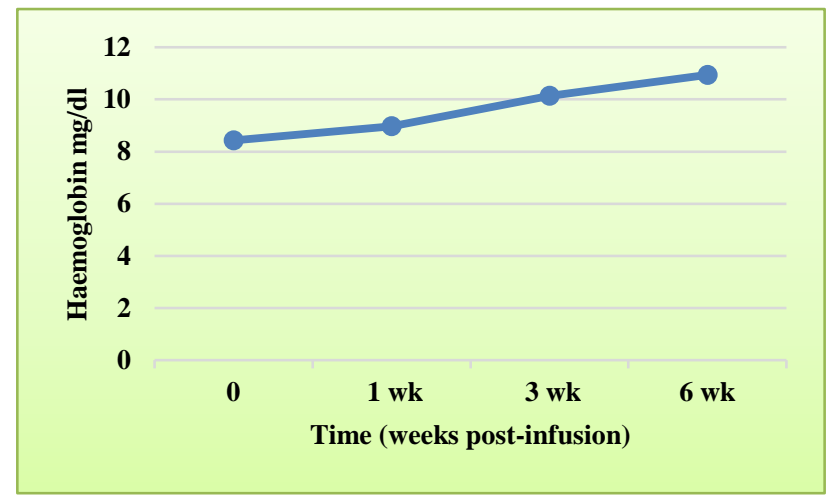

Figure 1: Mean haemoglobin levels (g/dL).

Change in haemoglobin concentration in the post infusion period presented in Figure 1. The post-infusion haemoglobin level was significantly higher at all subsequent visits $(p<0.01)$ than baseline haemoglobin values. There was a significant increase in haemoglobin levels from baseline to 6-week post-infusion (average increase $2.5 \mathrm{~g} / \mathrm{dl}$; $\mathrm{p}<0.01$ ). Ferritin values also increased significantly after the infusion. Post-partum ferritin levels were available for only four patients. Although, despite the limitation, values indicate replenished iron stores, with mean $( \pm \mathrm{SD})$ levels of $149 \mu \mathrm{g} / \mathrm{L}( \pm 5.3)$.

Of the 44 women interviewed, 33 (75\%) women reported sense of well-being, 7 (15.9\%) women could not feel any difference after the infusion and $4(9.1 \%)$ patients could not comment. FHR monitoring did not show any drug related unfavourable effect on the fetus. No serious adverse effects were noticed, 41 (93\%) patients didn't show any adverse effects but minor side effects occurred in $3(6.8 \%)$ patients (Table 2$)$.

Table 2: Complications of FCM.

\begin{tabular}{|ll|}
\hline Complications & Number(\%) \\
\hline None & $41(93.2 \%)$ \\
\hline Itching & $01(2.3 \%)$ \\
\hline Breathlessness & $01(2.3 \%)$ \\
\hline Urticarial & $01(2.3 \%)$ \\
\hline Total & 44 \\
\hline
\end{tabular}

\section{DISCUSSION}

This prospective study investigated the safety and efficacy of ferric carboxymaltose during pregnancy. The most important finding this study showed was, significant increase in $\mathrm{Hb}$ levels in pregnant women presenting with iron deficiency anemia. Therefore, ferric carboxymaltose is a safe and effective modality for correction of iron deficiency anemia in $2^{\text {nd }}$ and $3^{\text {rd }}$ trimester, with minimal adverse effects and rare presence of serious events like hypersensitivity, anaphylactic reactions or any other serious effects. The patient satisfaction and the sense of wellbeing was higher in the postnatal period. As per the protocol, most of the women received only a single dose of $1000 \mathrm{mg}$ of IV iron, very few number required more than one FCM vial due to persistent anemia. The advantage of the single dose of FCM is that it is supported by greater compliance.

Many women develop iron deficiency anemia during pregnancy, with both maternal and fetal complications. ${ }^{23}$ Ferritin levels form an important screening tool and low levels during first trimester represent significant iron deficiency. Oral iron should definitely be used as the first line weapon to combat anemia, however when drug intolerance is present because of medical comorbidities like malabsorption or inflammatory bowel disease which leads to non-compliance to oral iron therapy and in those conditions parenteral iron becomes a more effective weapon.

The present study is well in tune with certain observational studies on safety and efficacy of FCM that may help to decide on potential benefits and risks. Frosler et al performed a prospective observational study including 65 pregnant women in $2^{\text {nd }}$ and $3^{\text {rd }}$ trimester who received Ferric carboxymaltose. ${ }^{20}$

They assessed $\mathrm{Hb}$ values at baseline and then at 3,6 and 8 weeks. After FCM administration all patients showed significant increase in $\mathrm{Hb}$ values and $66 \%$ patients reported an improved sense of wellbeing in postpartum period. No serious adverse effects were reported. Minor side effects occurred in $13(20 \%)$ patients and were nearly self-limiting. 
Christopher et al and Naqash et al had also compared the safety of FCM in comparison to other iron preparations and they helped to identify, the superiority of FCM over other preparations. ${ }^{24,25}$ The most recent study by Froessler also concluded that Ferric carboxymaltose infusion corrects iron deficiency or various degrees of iron deficiency anemia efficaciously and safely pregnant women and does not cause hemoconcentration. ${ }^{26}$

The most important problem of other iron dextran preparations is low dosage with multiple injections for correction of anemia. This could overcome by the rapid delivery system of single dose of FCM, which offers an effective and promising method for correction of iron deficiency anemia in pregnant women. In obstetrics, blood transfusions nearly account for $3-4 \%$ of all transfusion events and the majority of these present following post-partum haemorrhage (PPH). ${ }^{27} \mathrm{PPH}$ is one of the leading cause of maternal mortality, and is estimated to occur at a rate of $13.1 \% .^{28}$ Although it's enormous clinical utility, blood transfusion is a treatment along with many adverse events and risk, and should ideally be avoided. In addition to it, blood is costly with its ever increasingly short supply. ${ }^{29}$ A large retrospective study showed much higher transfusion rates of $7.5 \%$ in pregnant women with clinical $\mathrm{PPH} .{ }^{30}$ And the current data suggests that improving $\mathrm{Hb}$, at a later stage of third trimester may also have shielded few mothers from the risks of transfusion. This spare resource as well as optimizes the health of mother.

Therefore, if we get an established tool in our armamentarium to combat anemia which may increase $\mathrm{Hb}$ in the third trimester and prevent the need for transfusion in case of PPH. The very fact that there is no life-threatening complication with FCM, it could prove to be definitely a safer preventive option to treat anemia in pregnancy.

Present study was limited in terms of number of cases enrolled in this study and ferritin levels not done after for every patient. Basically, there is need of more randomized controlled trials to establish the safety and efficacy of FCM in pregnancy with anemia.

\section{CONCLUSION}

The data for this prospective case series is consistent with other prospective and retrospective studies that administration of FCM in the second and third trimester is likely to be safe and effective in treating anemia of pregnancy. The safety and efficacy seems appropriate for both mother and child however in the absence of randomized controlled trials no definitive conclusion can be drawn.

\section{Funding: No funding sources} Conflict of interest: None declared

Ethical approval: The study was approved by the Institutional Ethics Committee

\section{REFERENCES}

1. Beard JL, Hendricks MK, Perez EM, Murray-Kolb LE, Berg A, Vernon-Feagans L, et al. Maternal iron deficiency anemia affects postpartum emotions and cognition. J Nutr. 2005;135(2):267-72.

2. WHO. The global prevalence of anaemia in 2011. Geneva: World Health Organization; 2015

3. Bergmann RL, Dudenhausen JW, Ennen JC, Kainer F, Rath W, Schmidt S, et al. Diagnosis and treatment of iron deficiency and anaemia during pregnancy and post partum. Obstet Gynecol. 2009;69(08):682-6.

4. Rahman MM, Abe SK, Rahman MS, Kanda M, Narita S, Bilano V, et al. Maternal anemia and risk of adverse birth and health outcomes in low-and middle-income countries: systematic review and meta-analysis. Am J Clin Nut. 2016;103(2):495-504.

5. Lone FW, Qureshi RN, Emmanuel F. Maternal anaemia and its impact on perinatal outcome in a tertiary care hospital in Pakistan. East Mediterr Health J. 2004;10(6):801-7.

6. Viteri FE. The consequences of iron deficiency and anaemia in pregnancy on maternal health, the foetus and the infant. Hemoglobin. 1997;90(310):250.

7. Villar J, Merialdi M, Gulmezoglu AM, Abalos E, Carroli G, Kulier R, et al. Nutritional interventions during pregnancy for the prevention or treatment of maternal morbidity and preterm delivery: an overview of randomized controlled trials. J Nutr. 2003;133(5):1606S-25S.

8. Reveiz L, Gyte GM, Cuervo LG. Treatments for iron-deficiency anaemia in pregnancy. Cochrane Database Syst Rev. 2007(2).

9. Corwin EJ, Murray-Kolb LE, Beard JL. Low hemoglobin level is a risk factor for postpartum depression. J Nutr. 2003;133(12):4139-42.

10. Van Wyck DB, Martens MG, Seid MH, Baker JB, Mangione A. Intravenous ferric carboxymaltose compared with oral iron in the treatment of postpartum anemia: a randomized controlled trial. Obstet Gynecol. 2007;110(2):267-78.

11. Breymann C, Huch R. Anaemia in pregnancy and the puerperium. Uni-Med Verlag; 2008.

12. Bresani CC, Braga MC, Felisberto DF, Tavares-deMelo CE, Salvi DB, Batista-Filho M. Accuracy of erythrogram and serum ferritin for the maternal anemia diagnosis (AMA): a phase 3 diagnostic study on prediction of the therapeutic responsiveness to oral iron in pregnancy. BMC Preg Childbirth. 2013;13(1):13.

13. Bencaiova G, Breymann C. Mild anemia and pregnancy outcome in a swiss collective. J Preg. $2014 ; 2014$.

14. Woteki CE, Earl R, eds. Iron deficiency anemia: recommended guidelines for the prevention, detection, and management among US children and women of childbearing age. National Academies Press; 1994.

15. Cancelo-Hidalgo MJ, Castelo-Branco C, Palacios S, Haya-Palazuelos J, Ciria-Recasens M, Manasanch J, 
et al. Tolerability of different oral iron supplements: a systematic review. Curr Med Res Opin. 2013;29(04):291-303.

16. Moretti D, Goede JS, Zeder C, Jiskra M, Chatzinakou V, Tjalsma $\mathrm{H}$, et al. Oral iron supplements increase hepcidin and decrease iron absorption from daily or twice-daily doses in irondepleted young women. Blood. 2015;126(17):19819.

17. Camaschella C. Iron-deficiency anemia. N Engl J Med. 2015;372(19):1832-43.

18. Chertow GM, Hsu CY, Johansen KL. The enlarging body of evidence: obesity and chronic kidney disease. J Am Soc Nephrol. 2006;17(6):1501-2.

19. Khalafallah AA, Dennis AE. Iron deficiency anaemia in pregnancy and postpartum: Pathophysiology and effect of oral versus intravenous iron therapy. J Pregnancy. 2012;2012:10.

20. Froessler B, Cocchiaro C, Saadat-Gilani K, Hodyl N, Dekker G. Intravenous iron sucrose versus oral iron ferrous sulfate for antenatal and postpartum iron deficiency anemia: a randomized trial. J Matern Fetal Neonatal Med. 2013;26(7):654-9.

21. Bhandal N, Russell R. Intravenous versus oral iron therapy for postpartum anaemia. BJOG. 2006;113(11):1248-52.

22. Milman N, Bergholt T, Byg KE, Eriksen L, Graudal $\mathrm{N}$. Iron status and iron balance during pregnancy. A critical reappraisal of iron supplementation. Acta Obstet Gynecol Scand. 1999;78(9):749-57.

23. Beris $\mathrm{P}$, Maniatis A. On behalf of the NATA working group on intravenous iron therapy. Guidelines on intravenous iron supplementation in surgery and obstetrics/gynecology. Transfus Altern Transfus Med. 2007;9(Suppl 1):29.

24. Christoph P, Schuller C, Studer H, Irion O, De Tejada BM, Surbek D. Intravenous iron treatment in pregnancy: comparison of high-dose ferric carboxymaltose vs. iron sucrose. J Perinatal Med. 2012;40(5)469-74.

25. Naqash A, Ara R, Bader GN. Effectiveness and safety of ferric carboxymaltose compared to iron sucrose in women with iron deficiency anemia: phase IV clinical trials. BMC Women's Health. 2018;18(1):6.

26. Froessler B, Gajic T, Dekker G, Hodyl N. Treatment of iron deficiency and iron deficiency anemia with intravenous ferric carboxymaltose in pregnancy. Arch Gynecol Obstet. 2018;298(1):75-82.

27. Catling S. Blood conservation techniques in obstetrics: a UK perspective. Int J Obstet Anesth. 2007;16(3):241-9.

28. Roberts CL, Ford JB, Thompson JF, Morris JM. Population rates of haemorrhage and transfusions among obstetric patients in NSW: a short communication. Aus N Z J Obstet Gynaecol. 2009;49(3):296-8.

29. Ferraris VA, Davenport DL, Saha SP, Austin PC, Zwischenberger JB. Surgical outcomes and transfusion of minimal amounts of blood in the operating room. Arch Surg. 2012;147(1):49-55.

30. Bonnet MP, Deneux-Tharaux C, Dupont C, Rudigoz $\mathrm{RC}$, Bouvier-Colle MH. Transfusion practices in postpartum hemorrhage: a population-based study. Acta Obstet Gynecol Scand. 2013;92(4):404-13.

Cite this article as: Bhatt RK, Rao PS, Sharma S, Yadav C. Ferricarboxy maltose to treat iron deficiency anemia in pregnancy: is it a feasible option?. Int J Reprod Contracept Obstet Gynecol 2019;8:19-23. 